\title{
Abnormal Lipoprotein Lipase in
}

\section{Familial Exogenous Hypertriglyceridemia}

\author{
Paul H. Schreibman, Daniel L. Arons, Christopher D. Saudek, and \\ RoNALd A. ARKY \\ From the Thorndike Memorial Laboratory, Harvard Medical Unit, Boston City \\ Hospital and the Department of Medicine, Harvard Medical School, \\ Boston, Massachusetts 02118
}

\begin{abstract}
A в S T R A C T A 5-yr old male proband and his sister have had hypertriglyceridemia and hepatosplenomegaly since birth. When studied on a metabolic ward, they demonstrated rapid decreases in serum triglycerides on $3 \mathrm{~g}$ fat/day diets. Oral glucose tolerance tests were normal. Postheparin lipolytic activity (PHLA) against chylomicrons was virtually absent in both children whereas the mother and a normolipemic sister had levels approximately $50 \%$ normal. However, all four had a normal PHLA against commercial triglyceride emulsion (Intralipid). Two unrelated children from different kindreds of typical type I hyperlipoproteinemia and two patients with acquired type $\mathrm{V}$ hyperlipoproteinemia had deficient PHLA against both substrates. No inhibitors of PHLA could be demonstrated in the proband's plasma, and his own PHLA could not be enhanced by either normal concentrated plasma or pooled $d>1.063$ lipoprotein fraction. The proband's postheparin plasma required almost 20 times the normal chylomicron-triglyceride concentration to reach one-half maximal lipase velocity.
\end{abstract}

Both affected siblings showed heavy pre-beta lipoprotein electrophoretic bands plus chylomicrons in their fasting plasmas while ingesting a $33 \%$ carbohydrate, $30 \%$ fat diet. Incubation of their postheparin plasma with $\mathrm{S}_{\mathrm{r}}>400$ chylomicrons in vitro produced a smaller $\mathrm{S}_{\mathrm{f}}$ 20-400 "remnant" with pre-beta electrophoretic mobility that was not seen under the same conditions when normal postheparin plasma was used. Postheparin monoglyceridase and phospholipase activities were either normal or only moderately decreased when determined

Portions of this work have been reported at the Annual Meeting of the American Society of Clinical Investigation. J. Clin. Invest. 1971. 50: 82a. (Abstr.)

Dr. Schreibman's present address is The Rockefeller University, New York 10021.

Received for publication 14 August 1972 and in revised form 8 March 1973. with appropriate artificial substrates. These data are consistent with either $(a)$ a mutant gene producing a lipoprotein lipase with unusual substrate specificities or (b) an absolute deficiency of normal lipoprotein lipase with a compensatory increase in some other postheparin triglyceridase.

\section{INTRODUCTION}

In the rare, familial type I (exogenous, fat-induced, Burger-Grütz) hyperlipoproteinemia, the postabsorptive plasma appears creamy due to light-scattering chylomicrons. The plasma triglycerides are markedly elevated whereas cholesterol is normal or only slightly increased. The disorder is usually present from childhood and lipemia retinalis, eruptive xanthomata, hepatosplenomegaly, pancreatitis, or obscure bouts of abdominal pain accompany this entity (1). When dietary fat is restricted to $5 \mathrm{~g} /$ day, serum triglycerides and clinical signs both improve.

The defect in this disease appears to be a diminished removal of fat particles secondary to a deficiency of lipoprotein lipase, an enzyme facilitating the uptake of chylomicrons by extrahepatic tissues. Adipose tissue extracts from homozygous type I patients show low lipoprotein lipase activity whereas heterozygous carriers may have intermediate tissue levels (2). Our studies deal with a family demonstrating the usual clinical history and fat-induction characteristics of type I hyperlipoproteinemia who have an abnormal lipoprotein lipase with unusual substrate specificity and kinetics.

\section{METHODS}

All subjects avoided alcohol, excessive dietary fat or carbohydrate, tobacco, and medications (except where indicated in Table I) for $48 \mathrm{~h}$ preceding study. Venous blood was collected the morning after an overnight fast into heparinized or EDTA tubes and immediately centrifuged at $4^{\circ} \mathrm{C}$, 
$5,000 \mathrm{rpm}$. Plasma was either refrigerated at $4^{\circ} \mathrm{C}$ or frozen at $-20^{\circ} \mathrm{C}$ before analysis. Lipoprotein electrophoresis was performed within $24 \mathrm{~h}$ of collection by the method of Lees and Hatch (3). Plasma triglycerides (4) and cholesterol (5) were determined on the AutoAnalyzer (Technicon Instruments Corp., Tarrytown, N. Y.).

Postheparin enzyme assays were performed on plasma collected $6,8,10$, and 12 min after intravenous injection of $0.1 \mathrm{mg} / \mathrm{kg}$ aqueous heparin (Eli Lilly and Co., Indianapolis, Ind., $100 \mathrm{U} / \mathrm{mg}$ ). Lactescent plasmas were centrifuged at $106,000 \mathrm{~g}$ for $1 \mathrm{~h}$ at $4^{\circ} \mathrm{C}$ to remove chylomicrons that might serve as endogenous substrate or create pipetting errors. This $1 \mathrm{~h}$ centrifugation cleared all plasmas of any turbidity. For simplification, equal volumes of each sample were pooled for a given patient and enzyme assays were performed in duplicate on the single pooled specimen. Results obtained in this manner did not differ significantly from those derived from the mean activity of individual specimens taken 6-12 min after the injection of heparin.

Postheparin lipolytic activity $(P H L A) .^{1}$ Both Intralipid (Vitrum-Stockholm) and human chylomicrons were used as substrates for the lipoprotein lipase released by heparin. The Intralipid represents an artificial triglyceride emulsion (containing small amounts of phospholipid and monoglyceride) commonly used for the assay of PHLA. The chylomicrons represent the $S_{\mathrm{f}}>400$ fraction obtained by ultracentrifugation at plasma density, $40,000 \mathrm{rpm}$ for $60 \mathrm{~min}$ in a Spinco model $\mathrm{L}$ using a no. 40 fixed angle rotor (Beckman Instruments, Inc., Spinco Div., Palo Alto, Calif.). The source of this substrate was a chylous ascites effusion occurring in a patient with lymphatic obstruction secondary to retroperitoneal carcinoma. The uncentrifuged effusion was stored under sterile conditions at $4^{\circ} \mathrm{C}$ and served as a reproducible source of chylomicron substrate for periods up to $4 \mathrm{mo}$. The actual chylomicron concentrate, decanted after ultracentrifugation, showed gross aggregation with rising FFA concentrations after 1 wk of storage under similar conditions and was therefore prepared fresh each day experiments were performed. There was no difference in enzyme activity against these chylomicrons as compared with those obtained from hyperlipemic plasmas, including the proband's own postheparin chylomicrons. The final assay mixtures were as follows: (a)Chylomicrons. $0.3 \mathrm{ml}$ chylomicron suspension (135 $\mathrm{mg}$ triglyceride/ $\mathrm{ml}$ ) in $0.9 \%$ saline $(\mathrm{pH} 8.7), 0.3 \mathrm{ml} 0.33 \mathrm{M}\left(\mathrm{NH}_{4}\right)_{2} \mathrm{SO}_{4}$ in $20 \%$ fatty acid-poor albumin (Pentex-Bovine fraction V) ( $\mathrm{pH} 8.7$ ), $0.4 \mathrm{ml}$ plasma. Final $\mathrm{pH}$ after incubation ranged from 8.50-8.65. (b) Intralipid. $0.25 \mathrm{ml}$ of $10 \%$ Intralipid $(\mathrm{pH}$ $8.7), 0.25 \mathrm{ml} 0.4 \mathrm{M}\left(\mathrm{NH}_{4}\right)_{2} \mathrm{SO}_{4}$ in $20 \%$ fatty acid-poor albumin ( $\mathrm{pH} 8.7$ ), and $0.5 \mathrm{ml}$ plasma. The reaction in each assay was linear for $45 \mathrm{~min}$ and substrate concentrations were not rate-limiting. The entire incubation mixture was extracted for FFA determination (6) at 0 and $45 \mathrm{~min}$ in duplicate.

To test for circulating plasma inhibitors in the patient's plasma or for a missing component that might be supplied by normal plasma, the following experiments were performed (Table III). Identical PHLA assays with chylomicron substrates were done with the exception of the plasma component. Normal postheparin plasma was mixed with equal volumes of either preheparin plasma, plasma concentrated 10-fold with polyacrylamide gel (Lyphogel, Gelman Instrument Co., Ann Arbor, Mich.), or the $d>$

${ }^{1}$ Abbreviations used in this paper: PHLA, postheparin lipolytic activity; PHMA, postheparin monogyceridase activity.
1.063 fraction from either normal or patient's preheparin plasma to test for possible missing components necessary for full lipoprotein lipase activity.

Postheparin monoglyceridase activity (PHMA). A chromatographically pure mixture of 1 -, 2-monoolein ( $3 \mathrm{~g} / 100$ $\mathrm{ml}$ ) was added to Krebs-Ringer's phosphate buffer, $\mathrm{pH}$ 7.40, containing $10 \mathrm{~g} / 100 \mathrm{ml}$ FFA-poor albumin and 4 $\mathrm{g} / 100 \mathrm{ml}$ taurodeoxycholate and sonicated until clear. The resultant micellar suspension $(0.6 \mathrm{ml})$ served as a substrate for $0.4 \mathrm{ml}$ postheparin plasma. Samples were extracted at 0 and 90 min for FFA determinations. Results are expressed as microequivalents FFA released/milliliter plasma per hour. Preheparin plasma contains from 0.5 to $1.0 \mu \mathrm{eq} \mathrm{FFA/}$ $\mathrm{ml}$ per $\mathrm{h}$ monoglyceridase activity but was not assayed in all experiments and therefore the PHMA actually represents the sum of pre- and postheparin monoglyceridase activities.

Postheparin phospholipase. Inosthin, (Associated Concentrates, Woodside, N. Y.) a mixture of soybean phosphatides purified with acetone and ethanol, contains primarily phosphatidyl ethanolamine with trace sterol glycosides but no mono- or triglycerides. This was used as a substrate for phospholipase activity in postheparin plasma by a modification of the method described by Vogel and Zieve (7).

$10 \mathrm{ml}$ of $0.1 \mathrm{M}$ glycine buffer, $\mathrm{pH} 9.6$, containing $90 \mathrm{mg}$ Inosthin and $47.5 \mathrm{mg}$ sodium deoxycholate, was sonicated until clear. This suspension $(0.7 \mathrm{ml})$ was then mixed with $0.3 \mathrm{ml}$ plasma and incubated at $37^{\circ} \mathrm{C}$ for $1 \mathrm{~h}$ in duplicate. Samples for FFA determination were taken at 0 and $60 \mathrm{~min}$. The reaction was linear for $2 \mathrm{~h}$. Results are expressed as microequivalents FFA/milliliter plasma per hour.

Lipoprotein lipase: reaction products. To examine changes in size and composition of chylomicrons $\left(\mathrm{S}_{\mathrm{f}}>400\right.$ lipoproteins) after treatment with heparin-released plasma lipoprotein lipase, $6 \mathrm{ml}$ of either normal or patient's postheparin plasma was incubated with $6 \mathrm{ml}$ of chylomicrons suspended in $0.2 \mathrm{M}\left(\mathrm{NH}_{4}\right)_{2} \mathrm{SO}_{4}, 20 \%$ FFA-poor albumin, $\mathrm{pH} 8.7$, at $37^{\circ} \mathrm{C}$ for $4 \mathrm{~h}$. At intervals, portions were removed from each flask and either applied to Whatman $3 \mathrm{M}$ chromatographic paper strips for electrophoresis or added to cellulose nitrate ultracentrifuge tubes containing 0.9 $\mathrm{g} / 100 \mathrm{ml}$ saline plus $3 \mathrm{mg} / 10 \mathrm{ml}$ diethyl $p$-nitrosophenylphosphate (Paroxon-Calbiochem, San Diego, Calif), an inhibitor of lipoprotein lipase. The latter were then centrifuged at $106,000 \mathrm{~g}$ for $60 \mathrm{~min}$ to obtain the $\mathrm{S}_{\mathrm{f}}>400$ fraction. The remaining infranate was resuspended in saline and centrifuged at the same speed for $24 \mathrm{~h}$. The upper $2 \mathrm{ml}$ was considered as containing only the very low density $S_{f}$ 20-400 lipoprotein fraction. These migrated primarily in the pre-beta position with minor trailing from the origin on standard paper electrophoresis. Both $\mathrm{S}_{\mathrm{r}}>400$ and 20-400 fractions were extracted for triglyceride and cholesterol determinations. The incubations were performed once each on two separate days using different chylomicron preparations as substrates. The results were in good qualitative agreement and those of one such experiment are illustrated in Fig. 4.

Lipoprotein lipase: Michaelis-Menten kinetics. Postheparin plasma from four normal young males and the proband was incubated for $1 \mathrm{~h}$ with the following final chylomicrontriglyceride concentrations; $16.0,8.0,5.3,4.0,3.3$, and 1.6 $\mathrm{mg} / \mathrm{ml}$. The assay was otherwise identical with that described above for PHLA.

Buffer and plasma concentrations were constant at all substrate concentrations. One normal subject (no. 4) and the patient (Da. G.) received $0.5 \mathrm{mg} / \mathrm{kg}$ heparin IV in- 
TABLE I

Clinical and Biochemical Data for the G. Kinship

\begin{tabular}{|c|c|c|c|c|c|}
\hline $\begin{array}{l}\text { Patient } \\
\text { Age-Sex }\end{array}$ & $\begin{array}{c}\text { Pedigree } \\
\text { position }\end{array}$ & Triglycerides & Cholesterol & $\begin{array}{l}\text { Lipoprotein } \\
\text { electrophoresis }\end{array}$ & PHLA* \\
\hline & \multicolumn{3}{|c|}{$\mathrm{mg} / 100 \mathrm{ml}$} & & meq $F F A / m l$ plasma per $h$ \\
\hline $\begin{array}{c}\text { Normals } \\
\mathrm{n}=12\end{array}$ & - & $75-150$ & $75-250$ & - & $6.94 \pm 1.96$ \\
\hline $\begin{array}{l}\text { Da. G. } \\
5, \mathrm{M}\end{array}$ & III-1 & 935 & 125 & Chylomicrons $+\uparrow$ pre-beta & 0.14 \\
\hline $\begin{array}{l}\text { C. G. } \\
4, F\end{array}$ & III-2 & 4200 & 365 & Chylomicrons $+\uparrow$ pre-beta & 0.22 \\
\hline $\begin{array}{l}\text { Do. G. } \\
\quad 7, F\end{array}$ & III-3 & 83 & 158 & Normal & 2.46 \\
\hline $\begin{array}{l}\text { P. B. G. } \\
26, F\end{array}$ & II-3 & 223 & 157 & $\uparrow$ pre-beta (+trace chylomicrons) & 2.68 \\
\hline $\begin{array}{l}\text { S. G., Jr. } \\
29, \mathrm{M}\end{array}$ & II-2 & 360 & 212 & $\uparrow$ pre-beta + trace chylomicrons & 5.45 \\
\hline $\begin{array}{l}\text { S. G., Sr. } \\
60, M\end{array}$ & $\mathrm{I}-1$ & 310 & 276 & $\uparrow$ pre-beta & 9.42 \\
\hline $\begin{array}{l}\text { G. G. } \\
58, F\end{array}$ & $\mathrm{I}-2$ & 200 & 274 & $\uparrow$ pre-beta & 7.09 \\
\hline $\begin{array}{l}\text { D. G. } \\
\text { 32, } \mathrm{M}\end{array}$ & II-1 & 235 & 247 & $\uparrow$ pre-beta & 7.78 \\
\hline $\begin{array}{l}\text { A. B. } 8 \\
54, \mathrm{M}\end{array}$ & $\mathrm{I}-3$ & 342 & 295 & $\uparrow$ pre-beta & 5.75 \\
\hline $\begin{array}{l}\text { M. B. } \| \\
\quad 30, F\end{array}$ & II-4 & 60 & 223 & Normal & 4.42 \\
\hline $\begin{array}{l}\text { P. B. } \\
\text { 27, M }\end{array}$ & II-5 & 42 & 160 & Normal & 5.37 \\
\hline
\end{tabular}

* Postheparin lipolytic activity against chylomicrons: mean \pm SD.

$\ddagger$ Obesity and congestive heart failure controlled on digitalis and chlorothiazide.

$\S$ Subject ingested approximately $120 \mathrm{~cm}^{3}$ of 87 proof whiskey, 8-10 h preceding study.

|| Subject was in the 4th mo of pregnancy.

stead of the usual $0.1 \mathrm{mg} / \mathrm{kg}$ dose. This was done in the latter to obtain sufficient PHLA at lower substrate levels. The one normal subject served as a control to eliminate possible heparin effects on the substrate-enzyme complex at this relatively low plasma substrate concentration. The results in Fig. 5 are illustrated as reciprocal plots of velocity and substrate (Lineweaver-Burk) with the latter expressed in millimolar concentrations. The average molecular weight of chylomicron triglyceride was estimated at 900.

\section{RESULTS}

Table I and Fig. 1 provide the data establishing a genetic basis for the disorder in this kinship. There was a virtual absence of PHLA against chylomicrons in the two affected siblings with approximately $50 \%$ normal PHLA in the unaffected mother and sister. However, the proband's father has a low normal PHLA with trace chylomicrons in the fasting state and, as with the remaining family, cannot be definitely established as a carrier. It should be especially noted that the paternal grandparents are well within the normal range for PHLA. Elevated pre-beta lipoproteins were found in several asymptomatic family members and the mother (II-3) also contained trace chylomicrons by electrophoresis.

The lipoprotein electrophoretograms (Fig. 2) demonstrate the presence of chylomicrons in the proband's serum while on a regular diet with a distinct decrease

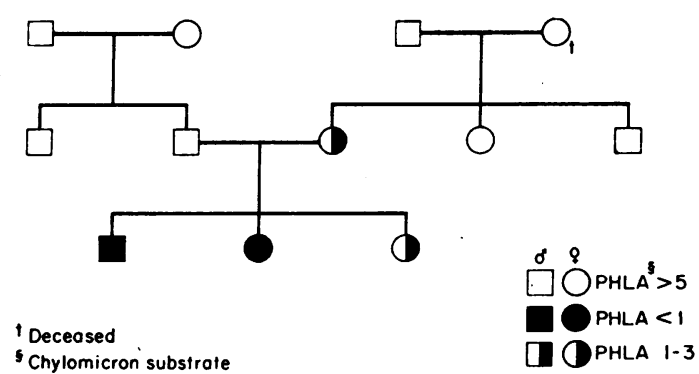

Figure 1 Pedigree for the G. family. There is no consanguinity known within the last four generations. Members are numbered (Table I) from left to right in each generation. 


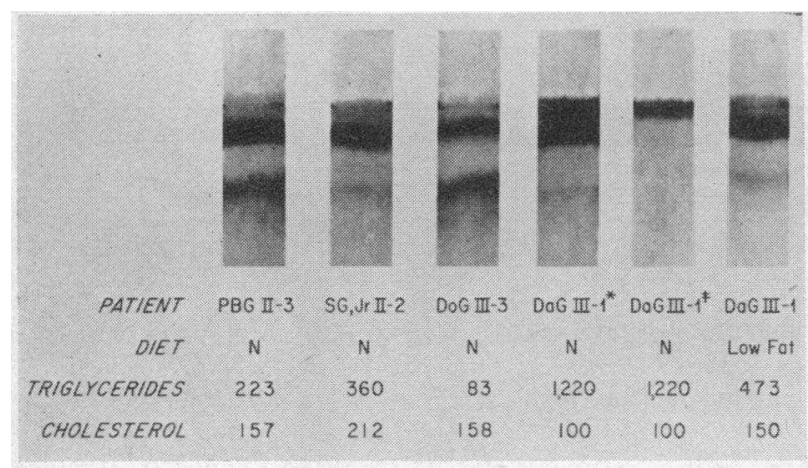

FIGURE 2 Lipoprotein electrophoretograms for the G. family. Serum triglycerides and cholesterol are in $\mathrm{mg} / 100 \mathrm{ml}$. * Undiluted plasma; $¥$ Same plasma diluted to $10 \% ; \mathrm{N}=$ normal diet.

after a period of fat restriction. In undiluted specimens there is a heavy accumulation of pre-beta species and a pronounced trail from the origin. When the plasma is diluted to $10 \%$ the electrophoretic pattern more clearly represents the typical finding in type I disorders.

Fig. 3 illustrates the sharp fall in serum triglycerides on a fat-restricted diet in the proband's younger sister after 10 days. She was then given a "normal" diet for 12 days to demonstrate the persistence of pre-beta, very low density lipoproteins. The carbohydrate content of this diet comprised $37 \%$ of the total calories. Not shown in the illustration was the continuing absence of PHLA against chylomicrons on this same diet that contained $30 \%$ of its total calories as fat. The PHLA measured against an artificial triglyceride emulsion and true chylomicrons are compared in Table II. All family members had a normal or low normal PHLA when measured against Intralipid. However, the two affected siblings had marked decreases in PHLA against chylomicrons

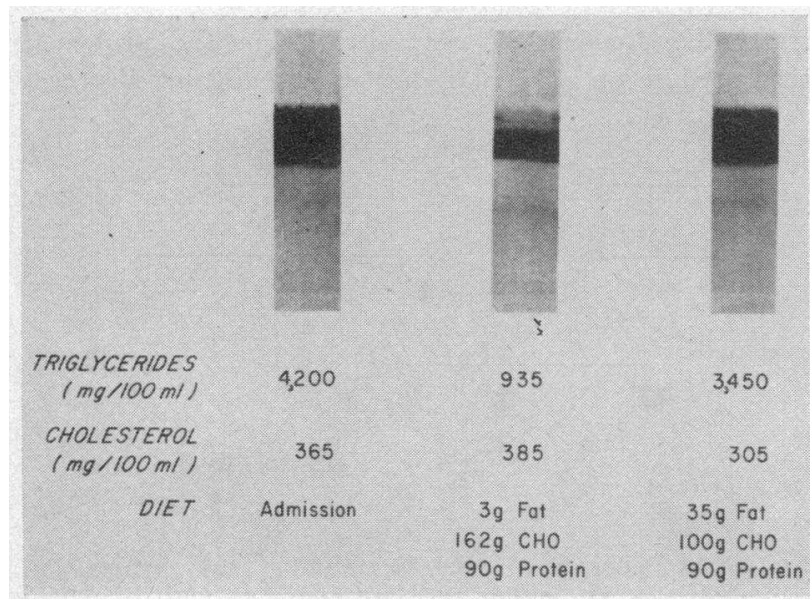

Figure 3 The effect of diet on serum triglycerides and cholesterol in the proband's sister, III-2. and the healthy sister and mother had approximately one-half the activity of normal subjects. The two unrelated type $I$ patients from different kinships and a type $\mathrm{V}$ patient with diabetes and pancreatitis all had very low PHLA with either substrate. Their postheparin plasmas were treated identically with the proband's including removal of plasma chylomicrons before assay.

The in vitro conversion of large $\mathrm{S}_{\mathfrak{t}}>400$ chylomicrons to smaller, very low density species with pre-beta electrophoretic mobility is shown in Fig. 4. The patient's plasma, which had low PHLA, catalyzed the change of triglyceride-rich, cholesterol-poor $\mathrm{S}_{\mathrm{r}}>400$ to a relatively cholesterol-rich chylomicron "remnant" (8) and a triglyceride-rich pre-beta particle. In effect, a purely exogenous type I phenotype was artificially converted to a mixed exogenous, endogenous type $\mathrm{V}$ (9) pattern as illustrated in the upper right panel.

The reaction kinetics of plasma lipoprotein lipase were examined in four normal subjects and the proband. The Lineweaver-Burk plots in Fig. 5 show close agreement in 'apparent' $K_{m}$ for the normals $(8.3-10.3 \mathrm{mM})$. However the patient's enzyme required almost 20 times

TABLE II

Postheparin Lipolytic Activity with Intralipid and True Chylomicron Substrates

\begin{tabular}{|c|c|c|}
\hline \multirow[b]{2}{*}{ Subject (pedigree position) } & \multicolumn{2}{|c|}{ PHLA } \\
\hline & Intralipid & Chylomicrons* \\
\hline & \multicolumn{2}{|c|}{$\mu e q F F A / m l$ per $h$} \\
\hline Normals $(n=12)$ & $6.22 \pm \mathrm{SD} 2.42$ & $6.94 \pm 1.96$ \\
\hline Da. G., III-1 & 3.90 & $\begin{array}{l}0.14 \\
1.20 \ddagger\end{array}$ \\
\hline C. G., III-2 & 4.40 & 0.22 \\
\hline & & $1.25 \ddagger$ \\
\hline Do. G., III-3 & 6.30 & 2.46 \\
\hline & & 3.27 \\
\hline P. B. G., II-3 & 4.10 & 2.68 \\
\hline & & $2.94 \ddagger$ \\
\hline M. B., II-4 & 5.60 & 4.42 \\
\hline P. B., II-5 & 6.92 & 5.37 \\
\hline A. B., I-3 & 10.47 & 5.75 \\
\hline A. I. $\S$ & 0.66 & 1.80 \\
\hline D. E.\| & 0.93 & 1.25 \\
\hline G. K. T & 0.27 & 1.80 \\
\hline
\end{tabular}

* Normolipemic donor of chylous ascites chylomicrons. $\ddagger$ Plasma chylomicrons from patient C. G. were used as substrate.

§ Type I-unrelated; patient of Dr. Gerald Salen, The Rockefeller University, New York.

|| Type I = unrelated; patient of Dr. Allen Crocker, Children's Hospital, Boston, Mass.

I Type $\mathrm{V}$ patient with diabetes mellitus and pancreatitis. 


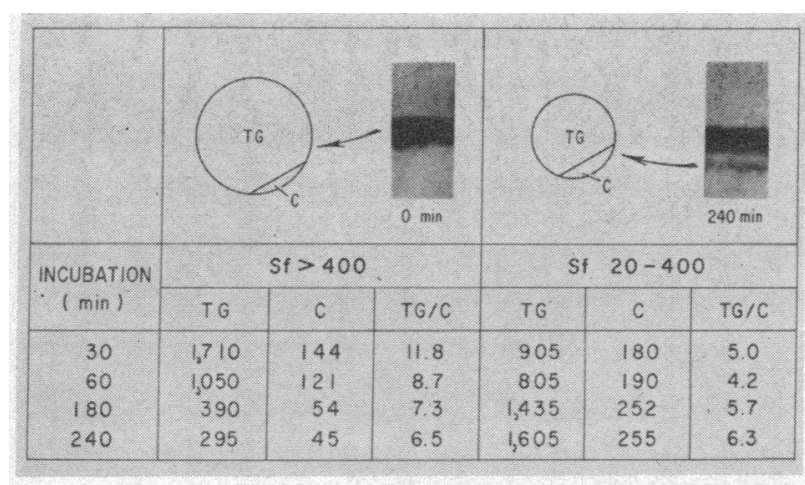

FIGURE 4 The reaction products of $S_{\mathrm{f}}>400$ chylomicrons after incubation with proband's postheparin plasma. The minutes listed at far left of the table indicate actual incubation time at $37^{\circ} \mathrm{C}$ but the substrate was exposed to enzyme throughout the approximately $3 \mathrm{~h}$ required for preparative ultracentrifugation and subsequent triglyceride extraction of the $S_{t}>400$ fraction. Although Paroxon was added to these samples, continuing transformation may have occurred to account for the measurement of $S_{\&} 20-400$ triglyceride at 30 and $60 \mathrm{~min}$ which did not appear on electrophoresis until 3 and $4 \mathrm{~h}$. Results for triglyceride (TG) and cholesterol (C) are in $\mathrm{mg} / 100 \mathrm{ml}$ incubation medium. No attempt was made to analyze $S_{t}$ 0-20 lipoproteins to possibly account for the "loss" of $24 \mathrm{mg} / 100 \mathrm{ml}$ cholesterol. Not shown are the following data obtained with normal postheparin plasma. The $\mathrm{S}_{\mathrm{f}}>400$ for $30 \mathrm{~min}$ was 545 and at $60 \mathrm{~min}, 50 \mathrm{mg} /$ $100 \mathrm{ml}$. The $S_{\mathrm{f}} 20-400$ was 15 at $30 \mathrm{~min}$ and $10 \mathrm{mg} / 100 \mathrm{ml}$ at $60 \mathrm{~min}$.

that chylomicron concentration to reach half-maximal velocity. If the patient's enzyme were merely deficient, then only the $y$ intercept $\left(1 / \mathrm{V}_{\max }\right)$ would differ from normal since $K_{m}$ is independent of enzyme concentration.

Table III eliminates an alternate explanation for the marked difference in 'apparent' $K_{m}$ shown in Fig. 5. The presence of plasma inhibitors may alter the enzyme-

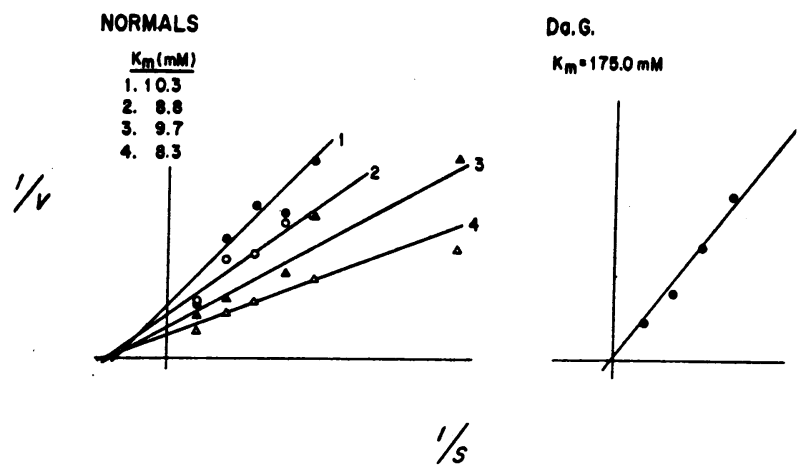

Figure 5 Lipoprotein lipase kinetics. Reciprocal plots of velocity and substrate concentration are shown for four normal subjects and the proband. The "apparent $K_{m}$ " is expressed as millimolar chylomicron-triglyceride concentration. The patient Da. G. and normal no. 4 received 0.5 $\mathrm{mg} / \mathrm{kg}$ heparin instead of usual dose of $0.1 \mathrm{mg} / \mathrm{kg}$.
TABLE III

Absence of PHLA-Inhibitors in Patient's Plasma or Enhancement of Patient's PHLA by Normal Plasma

\begin{tabular}{lc}
\hline \multicolumn{1}{c}{ Plasma } & PHLA* $^{*}$ \\
\hline & $\mu e q$ FFA $/ m l$ per $h$ \\
Normal postheparin & 10.76 \\
+normal preheparin & 9.76 \\
+Da. G's. preheparin & 9.94 \\
+normal preheparin (concentrated $\times 10)$ & 9.32 \\
+Da. G's. preheparin (concentrated $\times 10)$ & 10.59 \\
+normal $d>1.063$ & 10.38 \\
+Da. G. $d>1.063$ & \\
Da. G.'s postheparin & 1.33 \\
+normal preheparin & 1.13 \\
+Da. G.'s preheparin & 0.77 \\
+normal $d>1.063$ & 1.05 \\
+Da. G.'s $d>1.063$ & \\
\hline
\end{tabular}

* Chylomicron substrate.

substrate complex in such a way as to account for the above results. However there was not significant inhibition of normal PHLA detected by the $d>1.063$ plasma fraction. In Table III, data fail to show any missing components necessary for lipoprotein lipase activation that might have been supplied by addition of normal plasma or normal plasma high density lipoprotein.

Table IV lists the postheparin monoglyceridase and phospholipase activities in selected patients. Monoglyceridase remained in the normal or low normal range in all family members examined as well as in the two un-

TABLE IV

Postheparin Monoglyceridase and Phospholipase Activities

\begin{tabular}{|c|c|c|}
\hline \multirow[b]{2}{*}{ Patient } & \multicolumn{2}{|c|}{ Postheparin plasma activity } \\
\hline & Monoglyceridase & Phospholipase \\
\hline & \multicolumn{2}{|c|}{ meq $F F A / m l$ per $h$} \\
\hline Normals & $(\mathrm{n}=10) 7.93 \pm 1$ & $(n=4) 4.01 \pm 0.49^{*}$ \\
\hline Da. G. & 5.23 & 2.74 \\
\hline C. G. & 6.47 & 2.80 \\
\hline Do. G. & 5.70 & \\
\hline P. B. G. & 4.90 & \\
\hline P. B. & 8.00 & \\
\hline A. B. & 5.70 & \\
\hline A. I. $\neq$ & 4.57 & 2.20 \\
\hline D. E. $\ddagger$ & 5.10 & 2.86 \\
\hline G. K. $\S$ & 4.73 & 2.03 \\
\hline R.S. $\S$ & & 1.67 \\
\hline
\end{tabular}

$*$ Mean $\pm S D$.

$\ddagger$ Familial type I patients from unrelated kindreds.

$\$$ Acquired type $\mathrm{V}$ patients with diabetes mellitus and acute pancreatitis (see Table II for PHLA). 
related type $I$ patients and in a single patient with acquired PHLA deficiency (type V) secondary to poorly-controlled diabetes mellitus. The postheparin phospholipase was moderately decreased in all PHLAdeficient patients studied as compared with a small number of unmatched normal subjects.

\section{DISCUSSION}

The inheritance of type I hyperlipoproteinemia is established as autosomal recessive (1). Harlan, Winesett, and Wasserman (2) have phenotyped a family with exogenous hypertriglyceridemia on the basis of adipose tissue levels of lipoprotein lipase and were able to detect intermediate enzyme levels in the parents and one unaffected sibling. They further suggested an oral fat tolerance test as a useful tool for identifying carriers of this trait. However, this procedure has proven highly variable with normal volunteers in our laboratory and may be influenced by factors other than plasma PHLA (10) such as the fasting level of plasma triglyceride. In the family reported here, measurement of plasma PHLA was intermediate for the mother and healthy sister but was essentially normal in the father who would also be expected to be heterozygous for an abnormal gene. The most likely interpretation of these data is that of autosomal recessive transmission, however, PHLA determinations are not always a sensitive method for detection of heterozygotes. The significance of elevated pre-beta lipoproteins in other family members is unclear from our studies. Little, Whayne, Bhagwat, Buckley, and Kallos (11) have reported an adult female with type I whose father had type IV but whose five other relatives were normal.

The finding of diminished PHLA against chylomicrons in this kindred is in agreement with others. However normal lipolytic activity against a triglyceride emulsion has generally not been found in other type I families $(2,12-15)$ and may represent a variant of this disorder. The deficient PHLA against both substrates in our type I patients of unrelated kindreds (A. I. and D. E., Table IV) further confirms this differentiating feature. A single patient in reference 13 with typical type I features repeatedly gave normal PHLA against Ediol. Further investigations of this case have been reported (16) and will be discussed below. Steiner (17) has studied a 20-yr old alcoholic male, with no clear family history of hyperlipemia, who had features of fatinduced hypertriglyceridemia, normal PHLA with coconut oil emulsion (Ediol), but a deficient activity against natural chylomicrons similar to our subjects. Studies of five diabetic patients with acquired fat-induced hyperlipemia failed to show this substrate specificity (18) and these observations have been extended by patient
G. K. (Table II) who had diabetes and acute pancreatitis.

Another abnormality is the markedly increased 'apparent $K_{m}$ ' against chylomicrons for the proband's PHLA. These $K_{m}$ values are referred to as apparent because they reflect the activities of nonpurified enzyme(s) on substrate particles that also vary in size. However, even with these limitations, the comparison between normals' and proband's plasma remains valid and meaningful. The lack of circulating inhibitors in his plasma confirms the reports of others (12-14) and eliminates this as an explanation for the altered substrate kinetics. This apparent requirement for very high chylomicron concentration $(15,000 \mathrm{mg}$ triglyceride [TG] $100 \mathrm{ml})$ before half-maximal clearing occurs, might explain the metabolic abnormality as well as the clinical condition. The elevated apparent $K_{m}$ indicates a different or mutant enzyme rather than simply a deficient normal one. Similar kinetics and very low PHLA were observed in postheparin plasma taken after a period of low-fat intake. Ultracentrifugation was not necessary because of the low chylomicron concentration and the possibility of artifact, introduced by removal of chylomicron-bound enzyme, is therefore eliminated. Our data confirm those of Bradford, Furman, and Bass (14) who first demonstrated these kinetic differences with the coconut oil substrate (Ediol) in three siblings with familial hyperchylomicronemia. Their PHLA however, were markedly deficient against coconut oil triglycerides and there were also differences from normal seen with ionic and detergent inhibitor properties. This latter phenomenon may reflect an action on the enzyme-substrate complex formation rather than on the enzyme itself (19-20). Further studies on the kinetics of PHLA and substrate specificities must be performed on more cases of this disorder to clarify whether these two kindreds with unusual lipoprotein lipase properties are representative of familial hyperchylomicronemia.

An alternate explanation for the above data might be the compensatory increase of another postheparin triglyceridase that is absent or present in only small amounts in normal postheparin plasma. Others (21-23) have characterized a rat liver lipase showing differing $\mathrm{pH}$ and inhibitor properties from adipose tissue lipoprotein lipase. Herbert et al. (16) have recently reported that postheparin plasma from four type I patients hydrolyzed artificial glyceride emulsions but had different inhibition and activation characteristics from normal postheparin plasmas. They speculate that this triglyceridase originates from the liver as suggested from rat experiments and may also be released by heparin into the circulation of normal subjects. These data, would offer an attractive explanation for our studies. 
Still another possible explanation for the high apparent $K_{m}$ in an assay system that expresses activity as FFA production from triglyceride, is that enzyme activity is influenced by the size of the lipoprotein-triglyceride particles. In vitro conversion of chylomicrons to "remnants" (9) was observed with our patients' postheparin plasma, but not with normal controls. The possibility exists that normally there are two postheparin triglyceridases (24), one having greater affinity for $\mathrm{S}_{\mathbf{r}}>$ 400 and the other for the smaller St 20-400 lipoproteins. If our patients had a deficiency only in the latter case then this would be reflected in an abnormally low PHLA as measured against heterogeneous particle size. However, this explanation is less tenable because of our experiments in which the disappearance of substrate was followed (Fig. 4). The hydrolysis by the patients' postheparin plasma of both particles, $S_{r}>400$ and $S_{t} 20$ 400 "remnants" was reduced as compared with normal postheparin plasma. This would suggest that the patients' postheparin plasma had a deficiency of both lipases.

The exogenous pre-beta species produced in vitro may represent the same lipoprotein seen on electrophoresis of all undiluted plasmas from these patients (Fig. 2). The failure to observe this spectrum of lipoprotein density shifts with normal postheparin plasma may merely reflect the increased affinity of normal lipoprotein lipase for chylomicron triglyceride with completion of hydrolysis at a much faster rate. In this regard, Hazzard, Porte, and Bierman (25) have recently demonstrated in vitro production of triglyceride-poor chylomicrons after $16 \mathrm{~h}$ incubation of lipemic, postprandial plasma obtained from type II, III, and V patients. In view of these considerations, it seems prudent not to ascribe the pre-beta lipoproteins observed in our patient's fasting plasma as necessarily being of "endogenous" origin.

Heparin releases at least three other enzyme activities into the circulation: monoglyceridase $(26,27)$, phospholipase $(7)$, and a nonspecific esterase $(26,27)$. We have measured the first two enzymes and found monoglyceridase activity to be normal or low normal in all patients with familial or acquired hyperchylomicronemia. The phospholipase was low but definitely present. Our findings suggest that these are distinct enzymes but do not exclude a mutant lipoprotein lipase with normal affinity for monoolein or phosphatidyl ethanolamine micelles but decreased activity for chylomicron triglyceride. Other workers have previously reported the varying characteristics of the postheparin lipases $(7,27-29)$ but a highly purified lipoprotein lipase preparation (30) still retains monoglyceridase activity. Another recent report documents the failure to separate phospholipase from lipoprotein lipase by a wide variety of fractionation tech- niques (31). Perhaps the simplest explanation for these data is that lipoprotein lipase has activity against each of these glycerides but other separate heparin-released lipases also exist.

\section{ACKNOWLEDGMENTS}

The excellent technical assistance of Mr. Timothy Mahoney and the services of the Thorndike Memorial Laboratory nurses and dietitians are gratefully acknowledged. We also express our appreciation to Captain Stephen Chernay, MC, Reese Airforce Base, Dr. Allen Crocker, Children's Hospital, Boston, Mass., and Dr. Gerald Salen, Rockefeller University, New York, for referring the patients to us.

This work was supported by Research Grant AM-11176 and Training Grant 2-A-5060 from the National Institutes of Arthritis and Metabolic Diseases, U. S. Public Health Service, and Grant FR-76 from the Division of Research Facilities and Resources. Dr. Schreibman was supported in part by the Admiral Capp Memorial Endowment Fund, Harvard Medical School.

\section{REFERENCES}

1. Fredrickson, D. S., and R. S. Lees. 1966. Familial hyperlipoproteinemia. In The Metabolic Basis of Inherited Disease. J. B. Stanbury, J. B. Wyngaarden, and D. S. Fredrickson, editors. McGraw-Hill Book Co., New York. 2nd edition. 437.

2. Harlan, W. R., Jr., P. S. Winesett, and A. J. Wasserman. 1967. Tissue lipoprotein lipase in normal individuals and in individuals with exogenous hypertriglyceridemia and the relationship of this enzyme to assimilation of fat J. Clin. Invest. 46: 239.

3. Lees, R. S., and R. L. Hatch. 1963. Sharper separation of lipoprotein species by paper electrophoresis in albumin-containing buffer. J. Lab. Clin. Med. 61: 518.

4. Kessler, G., and H. Lederer. 1965. Fluorometric measurement of triglycerides. In Automation in Analytical Chemistry: Technicon Symposia. L. T. Speggs, editor. Mediad, Inc., New York. 341.

5. Zlatkis, A., B. Zak, and A. J. Boyle. 1953. A new method for the direct determination of serum cholesterol. J. Lab. Clin. Med. $41: 486$.

6. Dole, V. P. 1956. A relation between non-esterified fatty acids in plasma and the metabolism of glucose. J. Clin. Invest. $35: 150$.

7. Vogel, W. C., and L. Zieve. 1964. Post-heparin phospholipase. J. Lipid Res. 5 : 177.

8. Redgrave, T. G. 1970. Formation of cholesteryl esterrich particulate lipid during metabolism of chylomicrons. J. Clin. Invest. 49: 465.

9. Fredrickson, D. S., R. I. Levy, and R. S. Lees. 1967. Fat transport in lipoproteins-an integrated approach to mechanisms and disorders. N. Engl. J. Med. 276: 34.

10. Wilson, D. E., P. H. Schreibman, A. C. Brewster, and R. A. Arky. 1970 The enhancement of alimentary lipemia by ethanol in man J. Lab. Clin. Med. 75: 264.

11. Little, J. A., T. F. Whayne, A. G. Bhagwat, G. C. Buckley, and A. Kallos. 1970. A case of Type I hyperlipoproteinemia unusually sensitive to dietary alcohol and fat with induction of lipemia. Clin. Res. 18: 736. (Abstr.) 
12. Havel, R. J., and R. S. Gordon, Jr. 1960. Idiopathic hyperlipemia: metabolic studies in an affected family. J. Clin. Invest. $39: 1777$.

13. Fredrickson, D. S., K. Ono, and L. L. Davis. 1963. Lipolytic activity of post-heparin plasma in hyperglyceridemia. J. Lipid Res. 4: 24.

14. Bradford, R. H., R. H. Furman, and H. B. Bass. 1968. Plasma post-heparin lipolytic activity in hyperchylomicronemia (fat-induced lipemia). Biochim. Biophys. Acta. 164: 172.

15. Ahrens, E. H., Jr., J. Hirsch, K. Oette, J. W. Farquhar, and Y. Stein. 1961. Carbohydrate-induced and fat-induced lipemia. Trans. Assoc. Am. Physicians Phila. 74: 134.

16. Herbert, P., J. LaRosa, R. Krauss, S. Lux, R. Levy, and D. Fredrickson. 1971. On the lipolytic defect in familial Type I hyperlipoproteinemia. J. Clin. Invest. 50: 44a. (Abstr.)

17. Steiner, G. 1968. Lipoprotein lipase in fat-induced hyperlipemia. N. Engl. J. Med. 279: 70.

18. Wilson, D. E., P. H. Schreibman, and R. A. Arky. 1969. Post-heparin lipolytic activity in diabetic patients with a history of mixed hyperlipemia: relative rates against artificial substrates and human chylomicrons. Diabetes. 18 : 562 .

19. Datta, D. V., and H. S. Wiggins. 1964. New effects of sodium chloride and protamine on human postheparin plasma 'lipoprotein' lipase activity. Proc. Soc. Exp. Biol. Med. $115: 788$.

20. Bimpson, T., and J. A. Higgins. 1969. The effect of $\mathrm{pH}$, sodium chloride and protamine sulphate on the formation of a complex between rat adipose-tissue lipoprotein lipase and chylomicrons. Biochim. Biophys. Acta. 187: 447.
21. Higgins, J. A., and C. Green. 1967. Properties of a lipase of rat-liver parenchymal cells. Biochim. Biophys. Acta. 144: 211.

22. Guder, W., L. Weiss, and O. Wieland. 1969. Triglyceride breakdown in rat liver: the demonstration of three different lipases. Biochim. Biophys. Acta. 187: 173.

23. Carter, J. R., Jr. 1967. Hepatic lipase in the rat. Biochim. Biophys. Acta. $137: 147$.

24. LaRosa, J. C., R. I. Levy, H. G. Windmueller, and D. S. Fredrickson. 1970. Evidence for two triglyceride lipases in post-heparin plasma. J. Clin. Invest. 49: 55a. (Abstr.)

25. Hazzard, W. R., D. Porte, Jr., and E. L. Bierman. 1970. Abnormal lipid composition of chylomicrons in Broad- $\beta$ disease (type III hyperlipoproteinemia). $J$. Clin. Invest. 49 : 1853.

26. Shore, B., and V. Shore. 1961. Heparin-released lipolytic and esterolytic activities of human and rabbit plasmas. Am. J. Physiol. 201: 915.

27. Biale, Y., and E. Shafrir. 1969. Lipolytic activity toward tri- and monoglycerides in postheparin plasma. Clin. Chim. Acta. 23 : 413.

28. Greten, H., R. I. Levy, and D. S. Fredrickson. 1969. Evidence for separate monoglyceride hydrolase and triglyceride lipase in post-heparin human plasma. $J$. Lipid Res. 10: 326.

29. Shaw, W. A., W. R. Harlan, C. Thomas, and P. Jezyk. 1970. The role of phospholipase $\mathrm{A}$ in hyperlipidemias. Clin. Res. 18: 54. (Abstr.)

30. Fielding, C. J. 1970. Human lipoprotein lipase 1. Purification and substrate specificity. Biochim. Biophys. Acta. 206: 109.

31. Vogel, W. C., and E. L. Bierman. 1970. Correlation between post-heparin lipase and phospholipase activities in human plasma. Lipids. 5 : 385. 